\title{
Survival and risk of adverse events in older patients receiving postoperative adjuvant chemotherapy for resected stages II-IIIA lung cancer: observational cohort study
}

\author{
Juan P Wisnivesky associate professor of medicine ${ }^{12}$, Cardinale B Smith assistant professor of \\ medicine ${ }^{34}$, Stuart Packer assistant professor of medicine ${ }^{3}$, Gary M Strauss professor of medicine ${ }^{5}$, \\ Linda Lurslurchachai project manager ${ }^{1}$, Alex Federman associate professor of medicine ${ }^{1}$, Ethan $\mathrm{A}$ \\ Halm professor of medicine ${ }^{6}$
}

${ }^{1}$ Division of General Internal Medicine, Mount Sinai School of Medicine, One Gustave L Levy Place, Box 1087, New York, NY 10029, USA; ${ }^{2}$ Division of Pulmonary, Critical Care and Sleep Medicine, Mount Sinai School of Medicine; ${ }^{3}$ Division of Hematology/Oncology, Tisch Cancer Institute, Mount Sinai School of Medicine; ${ }^{4}$ Division of Hertzberg Palliative Care Institute of the Brookdale Department of Geriatrics, Mount Sinai School of Medicine; ${ }^{5}$ Division of Medical Oncology, Tufts Medical Center, Boston, MA, USA; ${ }^{6}$ Departments of Internal Medicine and Clinical Sciences, University of Texas Southwestern Medical Center, Dallas, TX, USA

\begin{abstract}
Objective To compare the survival and risk of serious adverse events in older patients with stages II-IIIA non-small cell lung cancer treated with or without postoperative platinum based chemotherapy.

Design Observational cohort study.

Setting Cases of lung cancer in Surveillance Epidemiology and End Results registry linked to Medicare files, 1992-2005, and follow-up data to December 2007.
\end{abstract}

Participants 3324 patients aged more than 65 years with resected stages II-IIIA lung cancer.

Main outcome measures Primary outcome was overall survival and secondary outcome was the rate of serious adverse events among older patients treated with or without adjuvant chemotherapy.

Results Overall, $21 \%$ ( $n=684$ ) of patients received platinum based chemotherapy. Analyses adjusted, stratified, or matched by propensity scores showed that chemotherapy was associated with improved survival (hazard ratio range $0.78-0.81$ ). The beneficial effect of chemotherapy was also observed among patients treated with radiation therapy (0.75-0.77) or without radiation therapy (0.74-0.77); however, chemotherapy was not beneficial for patients aged 80 or more (1.32-1.46). Adjuvant chemotherapy was associated with an increased odds of serious adverse events (odds ratio $2.0,95 \%$ confidence interval 1.5 to 2.6$)$.

Conclusions Platinum based adjuvant chemotherapy is associated with reduced mortality and increased risk of serious adverse events in older patients with stages II-IIIA lung cancer. The magnitude of the benefit is similar to that observed in randomised controlled trials carried out among selected patients.

\section{Introduction}

Lung cancer is predominately a disease of older people, with the median age at diagnosis in the United States being 69 years. ${ }^{1}$ By 2030 an estimated 20\% of the US population will be older than $65 .{ }^{2}$ Given the increasing life expectancy and the higher incidence of lung cancer in older people, the management of such patients with resectable non-small cell lung cancer should become increasingly common in clinical practice.

About $40 \%$ of patients with non-small cell lung cancer present with stages I to IIIA disease, which may be amenable to resection and is potentially curable. ${ }^{34}$ Patients with stage I non-small cell lung cancer have five year survival rates of around $70 \%$ and are usually observed after surgical resection. ${ }^{5}$ Conversely, $40-65 \%$ of patients with stage II or IIIA disease who have undergone resection experience recurrence and may ultimately die from disease progression. ${ }^{6}$ Several phase III randomised controlled trials have shown the benefit of adjuvant platinum based chemotherapy in patients with stages II-IIIA non-small cell lung cancer. ${ }^{7-9}{ }^{10}$ Recent meta-analyses of these trials also showed a survival advantage of adjuvant platinum based chemotherapy. ${ }^{11-15}$ As a result, current guidelines recommend the use of adjuvant chemotherapy as the standard of care for patients with stages II-IIIA non-small cell lung cancer who have undergone resection. ${ }^{16}$ 
Randomised controlled trials of cancer are carried out under highly standardised protocols. Although the internal validity of these trials is strong, the generalisability of the results to older patients with lung cancer is unclear. Most of the studies evaluating the efficacy of adjuvant chemotherapy in non-small cell lung cancer enrolled highly selected participants with good functional status and a low number of comorbidities; thus including a limited number of older participants. ${ }^{7} 101718$ Consequently, the observed benefit and adverse effects of adjuvant chemotherapy in these randomised controlled trials may not reflect those expected for older patients treated in routine clinical practice. This lack of evidence on the effectiveness of adjuvant chemotherapy in older patients and concerns about greater risks of adverse events might lead to under-treatment and increased lung cancer mortality among such patients with non-small cell lung cancer.

We used data from the Surveillance Epidemiology and End Results (SEER) registry, a nationally representative, population based data source on cancer, linked to Medicare files to compare survival outcomes and rates of serious adverse events among older patients with stages II-IIIA non-small cell lung cancer treated with or without platinum based adjuvant chemotherapy in routine clinical practice.

\section{Methods}

The study was carried out with the 2009 release of the SEER-Medicare linked database, which includes cases of lung cancer diagnosed up to 2005 and follow-up data to December 2007. The SEER registry keeps a national database that collects information on all incident cases of cancer in selected areas of the United States, covering nearly $26 \%$ of the US population. ${ }^{19}$ From the SEER-Medicare database we selected patients aged more than 65 years with a diagnosis of stages II-IIIA non-small cell lung cancer between 1992 and 2005 and who underwent surgical resection (lobectomy or pneumonectomy). Among these cases we excluded patients in healthcare maintenance organisations or those without part B Medicare insurance (coverage for outpatient care) for whom we were not able to ascertain comorbidities and use of chemotherapy. ${ }^{20} \mathrm{We}$ also excluded patients who died during the perioperative period (within 30 days of surgery) or who were discharged to a nursing home after surgery, as they would have not been candidates for adjuvant chemotherapy. The final cohort consisted of 3324 patients with stages II-IIIA non-small cell lung cancer.

From the SEER-Medicare database we obtained sociodemographic information on characteristics such as age, sex, race or ethnicity, marital status, and estimated income. To evaluate the burden of comorbidities, we used the Deyo adaptation of the Charlson comorbidity index, applying lung cancer specific condition weights as described in the literature. ${ }^{21-23}$ From the SEER database we obtained data on tumour location, size, extension, involvement of lymph nodes, and histology. We classified histological subtypes into categories of adenocarcinoma, bronchioalveolar carcinoma, squamous cell carcinoma, large cell carcinoma, and other histological type.

We examined surgical treatment using information from the SEER-Medicare database. ${ }^{24}$ Using these data, we classified patients as having either a lobectomy or a pneumonectomy (SEER site specific surgical codes 30 to 70). From Medicare inpatient, outpatient, and physician files we identified those patients who experienced postoperative complications (extrapulmonary infections, cardiovascular complications, thromboembolic events, respiratory complications, reoperations, and transfusions) within 30 days of surgery. ${ }^{25-27}$
Use of radiation therapy was ascertained from the SEER database and Medicare claims. We classified patients as having received radiotherapy if they were coded in the SEER database as having received external beam radiation or if Medicare claims contained any code indicating use of radiation therapy within six months of cancer diagnosis. From Medicare files we identified patients treated with adjuvant chemotherapy. Using validated algorithms, we classified patients as being treated with chemotherapy if Medicare inpatient, outpatient, or physician claims contained any code indicating that the patient received platinum based chemotherapy within three months of surgery. ${ }^{28}$ Functional status is an important determinant of chemotherapy use. Although the SEER-Medicare database does not include information on patients' functional status, all the study participants were eligible for surgery, which should have effectively excluded patients with poor functional status. To indirectly assess patients' postoperative functional status, we used data from the Home Health Agency file to ascertain use of home health services such as home health aide, physiotherapy, speech therapy, occupational therapy, and medical social services. As beneficiaries must be homebound to be eligible for Medicare home services, we used this information as a proxy for poor functional status.

The primary study outcome, determined from Medicare data, was overall survival. Using information in the Medicare file we calculated survival times as the period from surgery to the date of death. We classified those surviving past 31 December 2007 (alive at the end of follow-up) as censored observations. The secondary study outcome was the rate of serious adverse events among older patients who did or did not receive adjuvant chemotherapy. Using a published algorithm, we defined serious adverse events as those requiring admission to hospital within 2-6 months of surgery (the usual period for occurrence of chemotherapy related adverse events). Serious adverse events were infection, fever, neutropenia, anaemia, thrombocytopenia, dehydration, nausea or emesis, acute renal dysfunction, and unspecified adverse events of systemic therapy. ${ }^{29}$ Additionally, we evaluated the number of patients who died within 12 weeks of initiation of chemotherapy (the typical duration of platinum based regimens) and number of patients with a diagnosis of neuropathy, a potential long term adverse event from chemotherapy, within two years of resection.

\section{Statistical analysis}

The $\chi^{2}$ test was used to evaluate differences in the distribution of baseline characteristics between patients who did or did not receive postoperative platinum based chemotherapy. We used propensity score methods to control for potential selection bias. The propensity score is a measure of the probability that a patient will receive adjuvant chemotherapy after resection on the basis of their baseline characteristics. We calculated propensity scores using a logistic model that included the patients' sociodemographic characteristics, comorbidities, and cancer related factors (tumour location, size, involvement of lymph nodes, and grade). Additionally, we included dummy variables in the propensity score model indicating whether the patients had postoperative complications or received home services, as these patients were probably less likely to receive adjuvant chemotherapy. Once the model was fitted, we used regression analysis to evaluate whether baseline covariates were balanced across study groups after adjusting for the estimated propensity scores.

To compare survival of patients who did or did not receive adjuvant chemotherapy we used Cox regression analysis 
adjusting for propensity scores in three ways. ${ }^{30}{ }^{31}$ Firstly, we included the propensity score as a continuous covariate in a Cox model comparing the survival of patients treated with and without chemotherapy. In a second approach we fitted a stratified Cox model according to fifths of propensity scores. Finally, we matched patients based on the propensity scores and compared the survival of patients treated with and without adjuvant chemotherapy using a marginal Cox model for correlated data. ${ }^{32}$ Adjuvant chemotherapy may be used in combination with postoperative radiotherapy. As radiotherapy is usually given concurrently or after chemotherapy this covariate was not included in the propensity score model. Thus we carried out secondary analysis adjusting for and stratifying the cohort by radiotherapy use to assess the effectiveness of chemotherapy among patients treated with and without postoperative radiotherapy. We also did secondary analyses to assess survival among patients treated with and without adjuvant chemotherapy separately for stage II and stage IIIA disease, and within strata according to the patients' age at diagnosis $(<70$, $70-79$, and $>80$ years). Finally, we repeated all the analyses controlling for year of diagnosis, to adjust for potential time trends in other aspects of lung cancer care.

The potential association of chemotherapy with increased survival may be confounded by the patients' functional status, an important determinant of treatment. To evaluate this possibility we carried out a sensitivity analysis to test whether differences in functional status could account for the magnitude of the observed association of postoperative chemotherapy with survival. ${ }^{33}$ In our analysis we used published data on the prevalence of poor functional status (Eastern Co-operative Oncology Group functional status >2) among patients with stages II-IIIA non-small cell lung cancer and the relative hazard of death associated with poor functional status, to evaluate the robustness of our findings across different scenarios. ${ }^{34} 35$

We calculated the unadjusted odds for serious adverse events, with $95 \%$ confidence intervals, for patients receiving adjuvant chemotherapy. To estimate the odds of serious chemotherapy related adverse events among patients receiving chemotherapy compared with those not receiving chemotherapy we used logistic regression analysis after adjusting for propensity scores. All analyses were done with SAS software and using two tailed $\mathrm{P}$ values.

\section{Results}

From SEER-Medicare database 3759 patients aged more than 65 with resected stage IIA, IIB, or IIIA non-small cell lung cancer were identified. Overall, 435 patients were excluded: 114 had undergone limited resection and 321 were discharged to a long term care facility; the final cohort consisted of 3324 patients with non-small cell lung cancer. In total, 684 (21\%, $95 \%$ confidence interval $19 \%$ to $22 \%$ ) patients received platinum based chemotherapy. The median follow-up time was 39 months. Table 1 shows the baseline characteristics of these patients. Those treated with adjuvant chemotherapy were younger $(\mathrm{P}=0.02)$ and more likely to be white $(\mathrm{P}=0.04)$ and married $(\mathrm{P}=0.001)$. The characteristics of tumours (histology and stage) also differed significantly between patients treated or not treated with adjuvant chemotherapy $(\mathrm{P}=0.005$ and $\mathrm{P}<0.001$, respectively). Patients who did not receive adjuvant chemotherapy had a higher burden of comorbidities $(\mathrm{P}=0.05)$ and were more likely to receive home services $(\mathrm{P}=0.04)$. Use of postoperative radiotherapy was more common among patients receiving adjuvant chemotherapy $(\mathrm{P}<0.001)$. Except for postoperative use of radiotherapy, all other covariates were well balanced among patients treated with and without adjuvant chemotherapy after adjustment for propensity scores (table 1).

Analyses using a Cox model that included the propensity score as a covariate showed that adjuvant chemotherapy was associated with significantly better overall survival (hazard ratio $0.80,95 \%$ confidence interval 0.72 to 0.89 ; table 2 ). Five year adjusted survival rates were $35 \%$ (95\% confidence interval $32 \%$ to $39 \%$ ) for patients treated with adjuvant chemotherapy compared with $27 \%$ (25\% to $29 \%$ ) for patients not treated. Patients who received adjuvant chemotherapy also had significantly better overall survival in analysis adjusting for radiotherapy use (hazard ratio $0.77,95 \%$ confidence interval 0.69 to 0.85 ) or when the analysis was limited to patients who were treated with radiotherapy $(0.77,0.68$ to 0.88$)$ and without radiotherapy $(0.77,0.64$ to 0.91$)$. The results remained unchanged when the analysis was restricted to patients with stage II $(0.71,0.60$ to 0.83$)$ and stage IIIA disease $(0.88,0.77$ to 1.00$)$. Analyses within age strata showed that adjuvant chemotherapy was associated with improved survival among patients aged less than 70 years $(0.74,0.62$ to 0.88$)$ and $70-79$ years $(0.82,0.71$ to 0.94$)$; however, the survival benefit was not observed among patients aged more than 80 years $(1.33,0.86$ to 2.06). The survival advantage of patients treated with chemotherapy persisted when the analyses were repeated using stratification or matching of study participants by propensity scores. Secondary analyses also showed that adjuvant chemotherapy was associated with improved survival after adjusting for year of diagnosis to control for potential trends in lung cancer treatment.

Sensitivity analyses showed that potential differences in the prevalence of poor functional status among patients treated with and without chemotherapy did not seem to explain the association between platinum based chemotherapy and survival. The adjusted association between adjuvant chemotherapy and improved survival persisted even if untreated patients were five times more likely to have a poor functional status and the hazard ratio for poor functional status was 1.5 (adjusted hazard ratio $0.88,95 \%$ confidence interval 0.79 to 0.9 ; table 3 ), or poor functional status was almost three times more common among untreated patients and the mortality risk for patients with poor functional status was twice that of patients with good functional status $(0.89,0.80$ to 0.99 ; table 3$)$.

Overall, 21 patients (3.1\%) died within 12 weeks after initiation of chemotherapy. Table 4 shows the percentage of older patients treated with or without adjuvant chemotherapy who were admitted to hospital for the diagnoses that might occur as a serious adverse event. Among patients treated with chemotherapy, $13.0 \%$ were admitted to the hospital for at least one of these diagnoses compared with $6.9 \%$ of patients who did not receive chemotherapy (odds ratio $2.0,95 \%$ confidence interval 1.5 to 2.6 ). The most common serious adverse events resulting in admissions to hospital among patients treated with adjuvant chemotherapy were anaemia $(8.6 \%, \mathrm{n}=59)$, dehydration $(6.7 \%, \mathrm{n}=46)$, and infection $(5.3 \%, \mathrm{n}=36)$. Patients who received chemotherapy also had an increased risk of admission to hospital for infection (1.8, 1.2 to 2.7), neutropenia (15.6, 7.1 to 34.1), dehydration (1.8, 1.3 to 2.7$)$, nausea or emesis $(2.9,1.5$ to 5.8$)$, anaemia (3.1, 2.2 to 4.4 ), thrombocytopenia (5.1, 1.1 to 23.1 ), and unspecified adverse events of systemic therapy (47.1, 6.1 to 363.1$)$. The frequency of admissions to hospital for fever $(1.7,0.5$ to 5.6$)$ and renal dysfunction $(0.6,0.2$ to 2.1$)$ did not differ significantly. The odds for neuropathy within two years of surgery were also increased among patients treated with chemotherapy $(1.4,1.2$ to 1.7$)$. Similar results were obtained in analyses adjusting for propensity scores (table 4). 


\section{Discussion}

Several randomised controlled trials have shown the efficacy of adjuvant platinum based chemotherapy after resection among patients with stages II-IIIA non-small cell lung cancer. ${ }^{9} 101718$ However, the generalisability of these results to the growing population of older patients with lung cancer is unclear. Using population based data, we found that adjuvant platinum based chemotherapy given to an unselected sample of older patients with stages II-IIIA non-small cell lung cancer in the non-trial setting was associated with a similar improvement in survival. However, patients receiving adjuvant chemotherapy were at increased risk of serious adverse events requiring admission to hospital, and the benefit of adjuvant chemotherapy was not observed among patients aged 80 or more years. Because the net benefits outweighed potential harms, these data should encourage doctors to more strongly consider the use of adjuvant chemotherapy among older patients.

\section{Importance of findings from observational studies}

Randomised controlled trials provide the strongest level of evidence on the potential efficacy of cancer treatments such as adjuvant chemotherapy. Patients are randomly allocated to the study arms protecting against potential imbalances in the distribution of prognostic factors among study groups. Consequently, the internal validity of the results of randomised controlled trials is high. Randomised controlled trials are, however, usually carried out in highly controlled settings, such as specialised tertiary care centres, by experienced clinical teams, following standardised protocols, with frequent follow-up visits, and are often limited to select younger patients with few if any major comorbidities. Thus, clinicians may be concerned about extrapolating results from randomised controlled trials to older, sicker patients more often encountered in real world practice settings. Observational data can be useful for assessing the potential benefit of cancer therapies as used in routine clinical practice. In this study we validated the results of randomised controlled trials among a large population based sample of older patients, suggesting that increased used of chemotherapy in this population may improve survival outcomes.

As with other solid tumours, lung cancer primarily affects older people. Despite the high incidence mortality from non-small cell lung cancer in older people, the likelihood of receiving stage appropriate treatment and, in particular, chemotherapy decreases with increasing age. ${ }^{36}$ Data from chemotherapy trials designed specifically for older patients with non-small cell lung cancer are lacking; however, there is limited information from post hoc analyses of randomised controlled trials about the potential effectiveness of adjuvant chemotherapy in older people. A retrospective analysis of the adjuvant vinorelbine and cisplatin in elderly patients (JBR.10) trial suggested that the benefit of adjuvant cisplatin based chemotherapy was similar among patients aged 65 or less compared with those who were older. ${ }^{38}$ Similarly, pooled data from randomised controlled trials of cisplatin based adjuvant chemotherapy also showed similar improvements in overall survival among patients aged less than $65,65-69$, and 70 or more. ${ }^{39}$ Our results extend these findings by showing that adjuvant platinum based chemotherapy is associated with improved survival in a nationally representative population of Medicare beneficiaries, which included patients with multiple comorbidities or suboptimal functional status. Additionally, our results suggest that adjuvant chemotherapy is effective when used alone or in combination with radiation therapy.

Comparative effectiveness research based on observational data does not provide the same level of evidence about the benefits of adjuvant chemotherapy as does a randomised controlled trial. In observational studies, decisions about use of adjuvant chemotherapy are influenced by patient preferences, doctors' judgment, and practice patterns. These factors can generate systematic differences in the distribution of prognostic factors among patients treated with and without chemotherapy, which act as confounders of the effect of treatment. However, in this study we used propensity score methods and sensitivity analysis to control for the potential effect of measured and unmeasured prognostic factors. Our analyses showed that adjuvant chemotherapy was associated with a $20 \%$ to $25 \%$ decreased hazard of death in older people, a survival advantage similar to that reported in meta-analyses of randomised controlled trials. ${ }^{14}$ The results of the sensitivity analyses showed that our results were robust to a wide range of assumptions about potential imbalances of the distribution of patients with poor functional status among the two study groups. Analyses carried out within age strata suggest that adjuvant chemotherapy is not associated with improved survival in patients aged 80 or more, thus doctors should carefully weigh up the potential benefits and harms of chemotherapy and discuss these with patients. These results are, however, based on post hoc analyses and the study was not designed or powered to evaluate the effectiveness of chemotherapy in the subgroup of patients aged 80 or more.

A common perception among oncologists is that older patients are at increased risk of serious adverse events from combination chemotherapy regimens including platinum based drugs. ${ }^{40}$ Moreover, given the limited life expectancy of some older patients, concerns are that the possible long term survival benefits of chemotherapy may not offset the potential risk of treatment related complications. Our study shows that adjuvant chemotherapy is associated with an increased risk of serious adverse events requiring admission to hospital. However, the number of deaths within 12 weeks of starting chemotherapy, the type of adverse events observed in our cohort, and the rate of serious adverse event related admissions to hospital were consistent with those reported in previous randomised controlled trials among younger patients. ${ }^{79} 17$ Despite the higher rates of admissions to hospital for chemotherapy related serious adverse events, there was a net survival benefit for those who received adjuvant chemotherapy.

\section{Strengths and limitations of the study}

Several strengths and limitations of this study should be noted. Firstly, the SEER-Medicare database is a comprehensive source of population based cancer data. Levels of ascertainment within participating areas have been reported to be as high as $98 \%$, indicating most eligible cases are captured in the registry. ${ }^{41}$ Additionally, more than $94 \%$ of the patients aged 65 or more in the SEER registry are included in the SEER-Medicare database. ${ }^{42}$ Thus our results should be highly generalisable to the older US population as a whole. However, patients aged less than 65 are not eligible for Medicare (except for those with disability or end stage renal disease). Additionally, we excluded patients who were enrolled in a health maintenance organisation or who did not have Medicare part B coverage; thus, we were not able to assess the effectiveness of chemotherapy among these groups.

Patients with stage IIIA non-small lung cancer and with involvement of multiple lymph node stations or bulky 
lymphadenopathy are not generally candidates for primary resection and are usually treated with combined chemotherapy and radiotherapy. ${ }^{43}$ Unfortunately, the SEER registry does not include data on the number of lymph nodes stations involved or the presence of bulky lymph node disease. Although some of these patients may undergo surgery, resection is generally carried out after neoadjuvant chemotherapy or radiotherapy. As we excluded all patients who received neoadjuvant therapy, it is unlikely that patients with multiple or bulky lymphadenopathy were included in the study cohort. Moreover, these patients have a worse prognosis and are more likely to receive postoperative chemotherapy if they undergo resection than patients with less extensive lymph node involvement. Thus, their inclusion would bias our results towards the null.

The SEER-Medicare database is one of the largest available sources of cancer data in the United States. Although the database contains detailed information on the most important prognostic factors for lung cancer, it does not include data on patients' functional status. All patients in the cohort, based on their functional status, were considered fit for surgery. However, other factors (such as organ dysfunction) may also influence doctors' decisions about use of adjuvant chemotherapy in older patients. We adjusted our analyses for some of these potential confounders, such as comorbidities and postoperative complications, and utilised home services use as a proxy for poor functional status. Moreover, sensitivity analyses suggested that potential higher rates of poor functional status among patients who were not treated with adjuvant chemotherapy are unlikely to explain the observed benefit of chemotherapy. Aggressive treatment of older patients with lung cancer can result in serious adverse events; thus, survival benefits may not be accompanied by improvements in quality of life. These concerns may be one of the reasons for lower rates of chemotherapy use among older patients with lung cancer. Although we could not assess the potential impact of chemotherapy on quality of life, multiple studies focusing on older patients and on those with lung cancer or other malignancies showed that most patients are willing to endure a relatively poor quality of life in exchange for increased survival time. ${ }^{44-46}$ Additionally, studies show that patients with cancer are in general willing to accept intensive chemotherapy and potential adverse effects for a relatively small chance of benefit. $^{47-49}$

\section{Conclusions and clinical implications}

In summary, these data suggest that older patients with resected stages II-IIIA non-small cell lung cancer treated with adjuvant platinum based chemotherapy in routine practice settings have an improved survival compared with those who do not receive chemotherapy. The survival advantage in this patient population is comparable to that observed in younger, highly selected patients enrolled in previous randomised controlled trials assessing the efficacy of adjuvant chemotherapy. However, patients who received chemotherapy in our cohort were at increased risk of serious adverse events requiring admission to hospital; a factor that can negatively impact quality of life. Thus doctors should discuss the potential benefits and disadvantages of adjuvant chemotherapy with older patients who have lung cancer before initiating treatment. Given the rapid increase in the older population with lung cancer, our findings suggest that more frequent use of adjuvant platinum based chemotherapy in this patient population may improve patients' survival outcomes.

We thank the Applied Research Branch, Division of Cancer Prevention and Population Science, National Cancer Institute; the Office of
Information Services, and the Office of Strategic Planning, Health Care Finance Administration; Information Management Services; and the Surveillance Epidemiology and End Results (SEER) programme tumour registries in the creation of the SEER-Medicare database. The interpretation and reporting of these data are the sole responsibilities of the authors.

Contributors: JPW, SP, GMS, and EAH conceived and designed the study. JPW and LL analysed and interpreted the data. JPW and CBS drafted the article. AF, CBS, GMS, and EAH critically revised the article for important intellectual content. CBS, LL, SP, GMS, AF, and EAH gave final approval of the article. JPW provided statistical expertise. JPW and EAH obtained funding. LL provided administrative, technical, and logistical support. All authors critically revised the manuscript and approved the submitted version. JPW is the guarantor.

Funding: This study was supported by the National Cancer Institute (R01CA131348-02). The funding source had no role in the study design, implementation, or the interpretation of the results. CBS was supported in part by a research supplement to promote diversity in health related research programme award (R01CA131348-03S1).

Competing interests: All authors have completed the ICMJE uniform disclosure form at www.icmje.org/coi_disclosure.pdf (available on request from the corresponding author) and declare: no support from any organisation for the submitted work; JPW has relationships with EHE International (member of research board), Novartis Pharmaceutical (lecture honorarium), and GlaxoSmithKline (chronic obstructive lung disease research grant) that might have an interest in the submitted work in the previous three years; CBS, GMS, EAH, AF, LL, and SP have no other relationships or activities that could appear to have influenced the submitted work.

\section{Ethical approval: Not required.}

Data sharing: No additional data available.

1 Ries LAG, Krapcho M, Mariotto A, Miller BA, Feuer EJ, Clegg L, et al. SEER cancer statistics review, 1975-2003. http://seer.cancer.gov/csr/1975_2003/.

2 Yancik R. Cancer burden in the aged: an epidemiologic and demographic overview. Cancer 1997;80:1273-83.

3 Morgensztern D, Ng SH, Gao F, Govindan R. Trends in stage distribution for patients with non-small cell lung cancer: a National Cancer Database survey. J Thorac Oncol 2010;5:29-33.

4 Yang P, Allen MS, Aubry MC, Wampfler JA, Marks RS, Edell ES, et al. Clinical features of 5,628 primary lung cancer patients: experience at Mayo Clinic from 1997 to 2003. Chest 2005;128:452-62.

5 Wisnivesky JP, Yankelevitz D, Henschke $\mathrm{Cl}$. The effect of tumor size on curability of stage I non-small cell lung cancers. Chest 2004;126:761-5.

6 Mountain CF. Revisions in the international system for staging lung cancer. Chest 1997:111:1710-7.

7 Douillard JY, Rosell R, De Lena M, Carpagnano F, Ramlau R, Gonzales-Larriba JL, et al. Adjuvant vinorelbine plus cisplatin versus observation in patients with completely resected stage IB-IIIA non-small-cell lung cancer (Adjuvant Navelbine International Trialist Association [ANITA]): a randomised controlled trial. Lancet Oncol 2006;7:719-27.

8 Strauss GM, Herndon JE 2nd, Maddaus MA, Johnstone DW, Johnson EA, Harpole DH, et al. Adjuvant paclitaxel plus carboplatin compared with observation in stage IB non-small-cell lung cancer: CALGB 9633 with the Cancer and Leukemia Group B, Radiation Therapy Oncology Group, and North Central Cancer Treatment Group Study Groups. J Clin Oncol 2008;26:5043-51.

9 Winton T, Livingston R, Johnson D, Rigas J, Johnston M, Butts C, et al. Vinorelbine plus cisplatin vs observation in resected non-small-cell lung cancer. N Engl J Med 2005;352:2589-97.

10 Arriagada R, Bergman B, Dunant A, Le Chevalier T, Pignon JP, Vansteenkiste J. Cisplatin-based adjuvant chemotherapy in patients with completely resected non-small-cell lung cancer. N Engl J Med 2004;350:351-60.

11 Arriagada R, Auperin A, Burdett S, Higgins JP, Johnson DH, Le Chevalier T, et al. Adjuvant chemotherapy, with or without postoperative radiotherapy, in operable non-small-cell lung chemotherapy, with or without postoperative radiotherapy, in operable non-small-cell

12 Hamada C, Tanaka F, Ohta M, Fujimura S, Kodama K, Imaizumi M, et al. Meta-analysis of postoperative adjuvant chemotherapy with tegafur-uracil in non-small-cell lung cancer. $J$ Clin Oncol 2005;23:4999-5006.

13 Hotta K, Matsuo K, Ueoka H, Kiura K, Tabata M, Tanimoto M. Role of adjuvant chemotherapy in patients with resected non-small-cell lung cancer: reappraisal with a meta-analysis of randomized controlled trials. J Clin Oncol 2004;22:3860-7.

14 Pignon JP, Tribodet H, Scagliotti GV, Douillard JY, Shepherd FA, Stephens RJ, et al. Lung adjuvant cisplatin evaluation: a pooled analysis by the LACE Collaborative Group. $J$ Clin Oncol 2008;26:3552-9.

15 Sedrakyan A, Van Der Meulen J, O'Byrne K, Prendiville J, Hill J, Treasure T. Postoperative chemotherapy for non-small cell lung cancer: a systematic review and meta-analysis. $J$ Thorac Cardiovasc Surg 2004:128:414-9.

16 Pisters KM, Evans WK, Azzoli CG, Kris MG, Smith CA, Desch CE, et al. Cancer Care Ontario and American Society of Clinical Oncology adjuvant chemotherapy and adjuvant 


\section{What is already known on this topic}

Randomised controlled trials have shown the efficacy of adjuvant chemotherapy for stage II-IIIA non-small cell lung cancer

\section{What this study adds}

Using data from a population based cancer registry, we showed that adjuvant chemotherapy is associated with improved survival among older patients with lung cancer treated in the community

radiation therapy for stages I-IIIA resectable non small-cell lung cancer guideline. J Clin Oncol 2007;25:5506-18

17 Scagliotti GV, Fossati R, Torri V, Crino L, Giaccone G, Silvano G, et al. Randomized study of adjuvant chemotherapy for completely resected stage I, II, or IIIA non-small-cell lung cancer. J Natl Cancer Inst 2003:95:1453-61.

18 Waller D, Peake MD, Stephens RJ, Gower NH, Milroy R, Parmar MK, et al. Chemotherapy for patients with non-small cell lung cancer: the surgical setting of the Big Lung Trial. Eur $J$ Cardiothorac Surg 2004;26:173-82.

19 National Cancer Institute. Surveillance, Epidemiology and End Results (SEER) Program Limited-Use Data (1973-2006).

20 Klabunde CN, Harlan LC, Warren JL. Data sources for measuring comorbidity: a comparison of hospital records and medicare claims for cancer patients. Med Care 2006:44:921-8.

21 Deyo RA, Cherkin DC, Ciol MA. Adapting a clinical comorbidity index for use with ICD-9-CM administrative databases. J Clin Epidemiol 1992;45:613-9.

22 Klabunde CN, Legler JM, Warren JL, Baldwin LM, Schrag D. A refined comorbidity measurement algorithm for claims-based studies of breast, prostate, colorectal, and lung cancer patients. Ann Epidemiol 2007:17:584-90.

23 Klabunde CN, Potosky AL, Legler JM, Warren JL. Development of a comorbidity index using physician claims data. J Clin Epidemiol 2000;53:1258-67.

24 Cooper GS, Virnig B, Klabunde CN, Schussler N, Freeman J, Warren JL. Use of SEER-Medicare data for measuring cancer surgery. Med Care 2002;40(suppl 8):43-8.

25 Brailer DJ, Kroch E, Pauly MV, Huang J. Comorbidity-adjusted complication risk: a new outcome quality measure. Med Care 1996:34:490-505.

26 Iezzoni LI, Daley J, Heeren T, Foley SM, Fisher ES, Duncan C, et al. Identifying complications of care using administrative data. Med Care 1994;32:700-15.

27 Kalish RL, Daley J, Duncan CC, Davis RB, Coffman GA, lezzoni LI. Costs of potentia complications of care for major surgery patients. Am J Med Qual 1995;10:48-54

28 Virnig BA, Warren JL, Cooper GS, Klabunde CN, Schussler N, Freeman J. Studying radiation therapy using SEER-Medicare-linked data. Med Care 2002;40(suppl 8):49-54

29 Du XL, Osborne C, Goodwin JS. Population-based assessment of hospitalizations for toxicity from chemotherapy in older women with breast cancer. $J$ Clin Oncol 2002;20:4636-42.

30 Kates M, Swanson S, Wisnivesky JP. Survival following lobectomy and limited resection for the treatment of stage I non-small cell lung cancer $<=1 \mathrm{~cm}$ in size: a review of SEER data. Chest 2011:139:491-6.

31 Wisnivesky JP, Halm E, Bonomi M, Powell C, Bagiella E. Effectiveness of radiation therapy for elderly patients with unresected stage I and II non-small cell lung cancer. Am J Respir Crit Care Med 2010;181:264-9.

32 Wei L, Lin D, Weissfeld L. Regression analysis of multivariate incomplete failure time data by modeling marginal distributions. J Am Stat Assoc 1989;84:1065-3.

33 Lin DY, Psaty BM, Kronmal RA. Assessing the sensitivity of regression results to unmeasured confounders in observational studies. Biometrics 1998;54:948-63.

34 Ando M, Ando Y, Hasegawa Y, Shimokata K, Minami H, Wakai K, et al. Prognostic value of performance status assessed by patients themselves, nurses, and oncologists in advanced non-small cell lung cancer. Br J Cancer 2001;85:1634-9.
35 Blagden SP, Charman SC, Sharples LD, Magee LR, Gilligan D. Performance status score: do patients and their oncologists agree? Br J Cancer 2003;89:1022-7.

36 Earle CC, Tsai JS, Gelber RD, Weinstein MC, Neumann PJ, Weeks JC. Effectiveness of chemotherapy for advanced lung cancer in the elderly: instrumental variable and propensity analysis. J Clin Oncol 2001:19:1064-70.

37 Earle CC, Venditti LN, Neumann PJ, Gelber RD, Weinstein MC, Potosky AL, et al. Who gets chemotherapy for metastatic lung cancer? Chest 2000;117:1239-46.

38 Pepe C, Hasan B, Winton TL, Seymour L, Graham B, Livingston RB, et al. Adjuvant vinorelbine and cisplatin in elderly patients: National Cancer Institute of Canada and Intergroup Study. J Clin Oncol 2007;25:1553-61.

39 Fruh M, Rolland E, Pignon JP, Seymour L, Ding K, Tribodet H, et al. Pooled analysis of the effect of age on adjuvant cisplatin-based chemotherapy for completely resected non-small-cell lung cancer. J Clin Oncol 2008;26:3573-81.

40 Gridelli $\mathrm{C}$, Shepherd FA. Chemotherapy for elderly patients with non-small cell lung cancer: a review of the evidence. Chest 2005;128:947-57.

41 Warren JL, Klabunde CN, Schrag D, Bach PB, Riley GF. Overview of the SEER-Medicare data: content, research applications, and generalizability to the United States elderly population. Med Care 2002:40(suppl 8):3-18.

42 Potosky AL, Riley GF, Lubitz JD, Mentnech RM, Kessler LG. Potential for cancer related health services research using a linked Medicare-tumor registry database. Med Care 1993;31:732-48.

43 Maas KW, El Sharouni SY, Smit EF, Schramel FM. Sequencing chemotherapy, radiotherapy and surgery in combined modality treatment of stage III nonsmall cell lung cancer. Curr Opin Pulm Med 2007:13:297-304.

44 Chu DT, Kim SW, Kuo HP, Ozacar R, Salajka F, Krishnamurthy S, et al. Patient attitudes towards chemotherapy as assessed by patient versus physician: a prospective observational study in advanced non-small cell lung cancer. Lung Cancer 2007;56:433-43

45 List MA, Rutherford JL, Stracks J, Pauloski BR, Logemann JA, Lundy D, et al. Prioritizing treatment outcomes: head and neck cancer patients versus nonpatients. Head Neck 2004;26:163-70.

46 Tsevat J, Dawson NV, Wu AW, Lynn J, Soukup JR, Cook EF, et al. Health values of hospitalized patients 80 years or older. HELP Investigators. Hospitalized Elderly Longitudinal Project. JAMA 1998;279:371-5.

47 Balmer CE, Thomas P, Osborne RJ. Who wants second-line, palliative chemotherapy? Psychooncology 2001;10:410-8.

48 Hirose T, Horichi N, Ohmori T, Kusumoto S, Sugiyama T, Shirai T, et al. Patients preferences in chemotherapy for advanced non-small-cell lung cancer. Intern Med 2005:44:107-13

49 Slevin ML, Stubbs L, Plant HJ, Wilson P, Gregory WM, Armes PJ, et al. Attitudes to chemotherapy: comparing views of patients with cancer with those of doctors, nurses, and general public. BMJ 1990;300:1458-60

\section{Accepted: 17 May 2011}

Cite this as: BMJ 2011;343:d4013 


\section{Tables}

Table 1| Baseline characteristics of patients with stages II-IIIA non-small cell lung cancer in Surveillance Epidemiology and End Results-Medicare database, 1992-2005. Values are numbers (percentages) unless stated otherwise

\begin{tabular}{|c|c|c|c|c|}
\hline \multirow[b]{2}{*}{ Characteristic } & \multirow[b]{2}{*}{ Adjuvant chemotherapy $(n=684)$} & \multirow[b]{2}{*}{$\begin{array}{l}\text { No adjuvant chemotherapy } \\
\qquad(n=2640)\end{array}$} & \multicolumn{2}{|c|}{$P$ value } \\
\hline & & & $\begin{array}{l}\text { Not adjusted for } \\
\text { propensity scores }\end{array}$ & $\begin{array}{c}\text { Adjusted for } \\
\text { propensity scores }\end{array}$ \\
\hline Mean (SD) age (years) & $71.5(4.3)$ & $73.4(5.1)$ & 0.02 & 0.96 \\
\hline Women & $304(44)$ & $1181(45)$ & 0.89 & 0.99 \\
\hline \multicolumn{5}{|l|}{ Race or ethnicity: } \\
\hline White & $609(89)$ & $2323(88)$ & \multirow[t]{4}{*}{0.04} & \multirow[t]{4}{*}{0.98} \\
\hline African-American & $44(6)$ & $129(5)$ & & \\
\hline Hispanic & - $^{*}$ & $35(1)$ & & \\
\hline Other & - & $152(6)$ & & \\
\hline Married & $465(68)$ & $1615(61)$ & 0.001 & 0.98 \\
\hline \multicolumn{5}{|l|}{ Median income in area of residence: } \\
\hline Lowest fourth & $137(20)$ & $617(23)$ & \multirow[t]{4}{*}{0.21} & \multirow[t]{4}{*}{0.98} \\
\hline Second fourth & $177(26)$ & $681(26)$ & & \\
\hline Third fourth & $167(25)$ & $639(24)$ & & \\
\hline Highest fourth & $201(29)$ & $696(27)$ & & \\
\hline \multicolumn{5}{|l|}{ Comorbidity score†: } \\
\hline $0-1$ & $313(46)$ & $1065(40)$ & \multirow[t]{4}{*}{0.05} & \multirow[t]{4}{*}{0.99} \\
\hline$>1-1.5$ & $222(32)$ & $898(34)$ & & \\
\hline$>1.5-2.5$ & $56(8)$ & $266(10)$ & & \\
\hline$>2.5$ & $93(14)$ & $411(16)$ & & \\
\hline Home services & $437(17)$ & $91(13)$ & 0.04 & 0.96 \\
\hline \multicolumn{5}{|l|}{ Histology: } \\
\hline Adenocarcinoma & $374(55)$ & $1251(47)$ & \multirow[t]{5}{*}{0.005} & \multirow[t]{5}{*}{0.98} \\
\hline Bronchioloalveolar cell carcinoma & $39(6)$ & $163(6)$ & & \\
\hline Squamous cell carcinoma & $209(31)$ & $956(36)$ & & \\
\hline Large cell carcinoma & $32(4)$ & $172(7)$ & & \\
\hline Other & $30(4)$ & $98(4)$ & & \\
\hline \multicolumn{5}{|l|}{ Tumour location: } \\
\hline Upper lobe & $378(55)$ & $1483(56)$ & \multirow[t]{4}{*}{0.40} & \multirow[t]{4}{*}{0.95} \\
\hline Middle lobe & $27(4)$ & $105(4)$ & & \\
\hline Lower lobe & $231(34)$ & $913(35)$ & & \\
\hline Other & $48(7)$ & $139(5)$ & & \\
\hline \multicolumn{5}{|l|}{ Cancer stage: } \\
\hline IIA & $80(12)$ & $362(14)$ & \multirow[t]{3}{*}{$<0.001$} & \multirow[t]{3}{*}{0.98} \\
\hline IIB & $216(32)$ & $1024(39)$ & & \\
\hline IIIA & $388(56)$ & $1254(48)$ & & \\
\hline \multicolumn{5}{|l|}{ Type of surgery: } \\
\hline Lobectomy & $604(88)$ & $2256(85)$ & \multirow[t]{2}{*}{0.06} & \multirow[t]{2}{*}{0.99} \\
\hline Pneumonectomy & $80(12)$ & $384(15)$ & & \\
\hline \multicolumn{5}{|l|}{ Postoperative radiation: } \\
\hline Yes & $417(61)$ & $1172(44)$ & $<0.001$ & $-\ddagger$ \\
\hline No & 267 (39) & $1468(56)$ & & \\
\hline
\end{tabular}

*Exact numbers not reported to maintain patient confidentiality.

†Deyo adaptation of Charlson comorbidity index. ${ }^{21-23}$

$\ddagger$ Radiation not included in propensity score model as it is not a pre-treatment characteristic. 


\begin{tabular}{|c|c|c|}
\hline \multirow[b]{2}{*}{ Model } & \multicolumn{2}{|c|}{ Hazard ratio $(95 \% \mathrm{Cl})$} \\
\hline & Not adjusted for radiation therapy & Adjusted for radiation therapy \\
\hline \multicolumn{3}{|l|}{ Primary analysis } \\
\hline \multicolumn{3}{|l|}{ Entire cohort: } \\
\hline Adjusting for propensity scores & $0.80(0.72$ to 0.89$)$ & 0.77 (0.69 to 0.85$)$ \\
\hline Stratified by propensity score fifths & 0.81 (0.73 to 0.89 ) & 0.77 (0.69 to 0.85$)$ \\
\hline Matched analysis & $0.78(0.70$ to 0.87$)$ & 0.74 (0.66 to 0.82$)$ \\
\hline \multicolumn{3}{|l|}{ Secondary analyses } \\
\hline \multicolumn{3}{|l|}{ Patients treated with radiation: } \\
\hline Adjusting for propensity scores & 0.77 (0.68 to 0.88$)$ & - \\
\hline Stratified by propensity score fifths & 0.77 (0.68 to 0.88$)$ & - \\
\hline Matched analysis & 0.75 (0.66 to 0.86$)$ & - \\
\hline \multicolumn{3}{|l|}{ Patients not treated with radiation: } \\
\hline Adjusting for propensity scores & $0.77(0.64$ to 0.91$)$ & - \\
\hline Stratified by propensity score fifths & $0.76(0.64$ to 0.91$)$ & - \\
\hline Matched analysis & 0.74 (0.62 to 0.89$)$ & - \\
\hline \multicolumn{3}{|l|}{ Stage II disease: } \\
\hline Adjusting for propensity scores & 0.71 (0.60 to 0.83$)$ & $0.67(0.57$ to 0.79$)$ \\
\hline Stratified by propensity score fifths & $0.70(0.60$ to 0.83$)$ & $0.66(0.56$ to 0.78$)$ \\
\hline Matched analysis & $0.70(0.60$ to 0.83$)$ & 0.67 (0.56 to 0.78$)$ \\
\hline \multicolumn{3}{|l|}{ Stage IIIA disease: } \\
\hline Adjusting for propensity scores & $0.88(0.77$ to 1.00$)$ & $0.85(0.74$ to 0.98$)$ \\
\hline Stratified by propensity score fifths & 0.89 (0.78 to 1.02$)$ & $0.86(0.75$ to 0.98$)$ \\
\hline Matched analysis & $0.86(0.75$ to 0.98$)$ & $0.83(0.72$ to 0.95$)$ \\
\hline \multicolumn{3}{|l|}{ Age $<70$ years: } \\
\hline Adjusting for propensity scores & 0.74 (0.62 to 0.88$)$ & $0.72(0.60$ to 0.86$)$ \\
\hline Stratified by propensity score fifths & 0.75 (0.63 to 0.90$)$ & 0.73 (0.61 to 0.87$)$ \\
\hline Matched analysis & $0.76(0.63$ to 0.90$)$ & 0.72 (0.61 to 0.86$)$ \\
\hline \multicolumn{3}{|l|}{ Age $70-79$ years: } \\
\hline Adjusting for propensity scores & $0.82(0.71$ to 0.94$)$ & $0.78(0.68$ to 0.89$)$ \\
\hline Stratified by propensity score fifths & $0.83(0.73$ to 0.96$)$ & $0.78(0.69$ to 0.90$)$ \\
\hline Matched analysis & $0.82(0.71$ to 0.93$)$ & 0.77 (0.67 to 0.89$)$ \\
\hline \multicolumn{3}{|l|}{ Age $\geq 80$ years: } \\
\hline Adjusting for propensity scores & $1.33(0.86$ to 2.06$)$ & $1.24(0.80$ to 1.99$)$ \\
\hline Stratified by propensity score fifths & 1.32 (0.84 to 2.05$)$ & $1.22(0.78$ to 1.90$)$ \\
\hline Matched analysis & $1.46(0.91$ to 2.34$)$ & $1.29(0.80$ to 2.08$)$ \\
\hline
\end{tabular}


Table 3 | Sensitivity analysis of potential effect of poor functional status on effectiveness of adjuvant chemotherapy

Poor functional status $(\%)^{*}$

No chemotherapy Chemotherapy

Hazard ratio for poor functional statust

$5 \quad 1.5$

1.5

1.5

1.5

1.5
1.5

1.5
1.5

1.5

1.7

1.7

1.75

1.75

1.75

2.0

2.0

2.0

$\begin{array}{ll}2.0 & 0.87(0.78 \text { to } 0.97) \\ 2.0 & 0.90(0.81 \text { to } 0.99)\end{array}$

\begin{tabular}{llll}
\hline 25 & 15 & 2.0 & $0.87(0.78$ to 0.97$)$ \\
\hline 40 & 25 & 2.0 & $0.90(0.81$ to 0.99$)$
\end{tabular}

Cl)

$\begin{array}{ll}0.84(0.76 \text { to } 0.93) \\ 1.5 & 0.88(0.79 \text { to } 0.98)\end{array}$

$0.87(0.78$ to 0.97$)$

$.50 .84(0.75$ to 0.93$)$

$1.5 \quad 0.85$ (0.77 to 0.95$)$

$1.75 \quad 0.86(0.77$ to 0.95$)$

$.75 \quad 0.87(0.78$ to 0.97$)$

$.75 \quad 0.90(0.81$ to 1.00$)$

$1.75 \quad 0.85(0.76$ to 0.95$)$

$1.75 \quad 0.88(0.79$ to 0.97$)$

0.87 (0.79 to 0.97$)$

$0.89(0.80$ to 0.99$)$

$0.93(0.84$ to 1.03$)$

*Functional status according to Eastern Co-operative Oncology Group functional status $>2$.

†Compared with good functional status. 
Table 4| Admissions to hospital for chemotherapy related serious adverse events among study participants

\begin{tabular}{|c|c|c|c|c|}
\hline \multirow[b]{2}{*}{ Adverse events } & \multicolumn{2}{|c|}{ No (\%) of patients admitted with adverse event } & \multirow[b]{2}{*}{ Odds ratio $(95 \% \mathrm{Cl})$} & \multirow{2}{*}{$\begin{array}{l}\text { Odds ratio }(95 \% \mathrm{Cl}) \text { adjusted for } \\
\text { propensity scores }\end{array}$} \\
\hline & Adjuvant chemotherapy & No adjuvant chemotherapy & & \\
\hline Infection & $36(5.3)$ & $79(3.0)$ & 1.8 (1.2 to 2.7$)$ & 2.0 (1.3 to 3.1$)$ \\
\hline Neutropenia & $>30(>4.4)$ & $\leq 11(<1)^{*}$ & 15.6 (7.1 to 34.1 ) & $17.1(7.6$ to 38.1$)$ \\
\hline Fever & $\leq 11(\leq 1.6)$ & $\leq 11(<1)^{\star}$ & $1.7(0.5$ to 5.6$)$ & $1.6(0.4$ to 5.7$)$ \\
\hline Dehydration & $46(6.7)$ & $97(3.6)$ & $1.8(1.3$ to 2.7$)$ & $1.9(1.3$ to 2.8$)$ \\
\hline Nausea or emesis & $15(2.1)$ & $20(0.8)$ & $2.9(1.5$ to 5.8$)$ & $2.6(1.2$ to 5.3$)$ \\
\hline Anaemia & $59(8.6)$ & $78(3.0)$ & $3.1(2.2$ to 4.4$)$ & $3.6(2.5$ to 5.2$)$ \\
\hline Thrombocytopenia & $\leq 11(\leq 1.6)$ & $\leq 11(<1)^{\star}$ & $5.1(1.1$ to 23.1$)$ & $8.3(1.7$ to 40.4$)$ \\
\hline Renal dysfunction & $\leq 11(\leq 1.6)$ & $19(0.6)$ & $0.6(0.2$ to 2.1$)$ & $0.7(0.2$ to 2.4$)$ \\
\hline $\begin{array}{l}\text { Unspecified adverse events of } \\
\text { systemic therapy }\end{array}$ & $\geq 11(\geq 1.7)$ & $\leq 11(<1)^{\star}$ & 47.1 (6.1 to 363.1 ) & 79.7 (9.9 to 635.9 ) \\
\hline
\end{tabular}

*Exact numbers not reported to maintain patient confidentiality. 